\title{
Follow up results of treatment of unstable angina by coronary angioplasty
}

\author{
GIUSEPPE STEFFENINO, BERNHARD MEIER, LEO FINCI, \\ WILHELM RUTISHAUSER
}

From the Cardiology Centre, University Hospital, Geneva, Switzerland

SUMMARY Eighty nine of 327 consecutive patients undergoing coronary angioplasty at a centre had unstable angina-defined as either a worsening of the frequency or the severity of chest pain or severe episodes of chest pain at rest with no evidence of acute myocardial infarction. Multivessel disease was present in 31 of these patients. Two or more vessels were dilated in the same procedure in one fifth of the patients. Primary success was obtained in $80(90 \%)$ patients. Acute myocardial infarction was a complication in four $(5 \%)$ patients, including two of four patients who needed emergency coronary bypass grafting. Follow up coronary angiography at a mean (SD) of $10(6)$ months in 57 patients showed restenosis in 21 (37\%): of these, 13 patients had repeat coronary angioplasty and three had elective coronary bypass grafting. All patients in whom angioplasty was initially successful were followed up for $10(6)$ months after the last angioplasty procedure. There were no deaths. One patient had sustained a myocardial infarction unrelated to the dilated vessel. Clinically, 74 patients improved by at least one New York Heart Association class and $40(50 \%)$ were symptom free and with no signs or symptoms of myocardial ischaemia on a stress test.

Coronary angioplasty offers long term symptomatic improvement at an acceptable risk in the majority of patients with unstable angina.

Patients with unstable angina are at increased risk of myocardial infarction and premature death. ${ }^{1}$ In the past 10 years there has been much discussion on the best way to manage such patients. ${ }^{23}$ Although chest pain is often controlled by bed rest and intensive medical treatment, a substantial percentage of patients none the less have early unfavourable outcomes on medical treatment alone ${ }^{4}$; this result is partially related to persistent silent ischaemia. ${ }^{5}$ Percutaneous transluminal coronary angioplasty is increasingly accepted as a form of revascularisation in patients with unstable angina. ${ }^{6-12}$ We report the results of a follow up of selected patients with unstable angina treated with coronary angioplasty.

\section{Patients and methods}

Between July 1983 and May 1985 a total of 327

Requests for reprints to Dr Bernhard Meier, Centre de Cardiologie, Hôpital Cantonal Universitaire, CH 1211, Geneva, Switzerland.

Accepted for publication 5 January 1987 patients underwent coronary angioplasty at our centre. Eighty nine patients had unstable anginadefined as either a worsening in the frequency or severity of chest pain or severe episodes of prolonged pain at rest shortly before admission with no electrocardiographic or enzymatic evidence of acute myocardial infarction. We studied $76(85 \%)$ men and 13 women (mean (SD) age 55(9) years). In 54 patients there was a history of old myocardial infarction. There was two and three vessel disease

Baseline clinical and angiographic data in patients treated with angioplasty

\begin{tabular}{ll}
\hline Variable & Data \\
\hline Patients & 89 \\
Age (years) & $55(9)(35-69)$ \\
Men & $85 \%$ \\
Left ventricular ejection & $62(11)(41-80)$ \\
fraction (\%) & $54(61 \%)$ \\
Old myocardial infarction & 58 patients \\
One vessel disease & 22 patients \\
Two vessel disease & 9 patients \\
Three vessel disease & \\
\hline
\end{tabular}


causing stenosis of $70 \%$ of the luminal diameter in 22 and nine patients respectively. Four $(5 \%)$ patients had had previous coronary angioplasty. The table summarises the baseline clinical and angiographic data. Patients were treated with nitrates, $\beta$ blockers, calcium antagonists, and aspirin. The degree of coronary stenosis was visually estimated as a percentage of the luminal diameter by two angiographers in multiple projections and results were averaged.

Coronary angioplasty was performed as previously described, ${ }^{13}$ after intravenous heparin $(10000 \mathrm{IU})$ and intracoronary isosorbide dinitrate $(0.2 \mathrm{mg})$ or nifedipine $(0.1 \mathrm{mg})$ or both. The transfemoral approach was used in all cases. Prolonged anticoagulation with intravenous heparin infusion was not used routinely after a successful procedure, but the patients received oral nifedipine 40 to $60 \mathrm{mg} /$ day and aspirin $100 \mathrm{mg} /$ day unless contraindicated. Primary success was considered to have been achieved if the following conditions were met: angiographic improvement of the lesion with no significant residual stenosis, improvement in the transstenotic pressure gradient (whenever available), absence of electrocardiographic or enzymatic evidence of myocardial infarction or need for coronary artery bypass grafting within 48 hours of the procedure, and improvement of at least two New York Heart Association functional classes for angina. In multivessel angioplasty success was defined as dilatation of at least the ischaemia related lesion. Transient electrocardiographic changes in leads V1-V5 were regarded as indicating lesions of the left anterior descending coronary artery, while changes in leads V6, I, aVL or II, III, and aVF were said to reflect a lesion in either the circumflex or the right coronary artery respectively. When no electrocardiographic changes had been recorded, the vessel that showed the most severe stenosis and perfused a myocardial region with at least partially preserved contraction was identified as the ischaemia related vessel. Treatment with aspirin $100 \mathrm{mg} /$ day was recommended to all patients after discharge and antianginal, hypotensive, or antiarrhythmic drugs were also given as clinically indicated.

The clinical follow up consisted of an interview, a physical examination, and a symptom limited stress test. The stress test was performed on a bicycle ergometer. The workload was increased by $25 \mathrm{~W}$ every three minutes, and the test was regarded as positive if the patient complained of typical chest pain or if ST segment depression of $\geqslant 1 \mathrm{~mm}$ appeared $0.08 \mathrm{~s}$ after the $\mathrm{J}$ point. A few patients lived a long way from the hospital and they were followed up by a questionnaire or a telephone interview.

We recommended that all patients should have follow up coronary angiography. Recurrence of stenosis was defined as loss of $\geqslant 50 \%$ of initial gain in luminal diameter at the site of angioplasty. When appropriate the $\chi^{2}$ test was used for statistical analysis. A $p$ value $<0.05$ was regarded as significant.

\section{Results}

Coronary angioplasty was attempted in 89 patients and was successful in $80(90 \%)$. In $18(20 \%)$ patients we were able to attempt coronary angioplasty on the same day as diagnostic coronary angiography. In $18(20 \%)$ patients two or more vessels were dilated during the same procedure (fig 1). Lesions of the left anterior descending coronary artery accounted for $54 \%$ of the 110 dilated vessels (fig 2). The mean (SD) diameter of stenosis was reduced from $84(12) \%$ to $25(10) \%$ and the mean transstenotic pressure gradient (available for 82 successfully

(89 patients, 110 vessels)

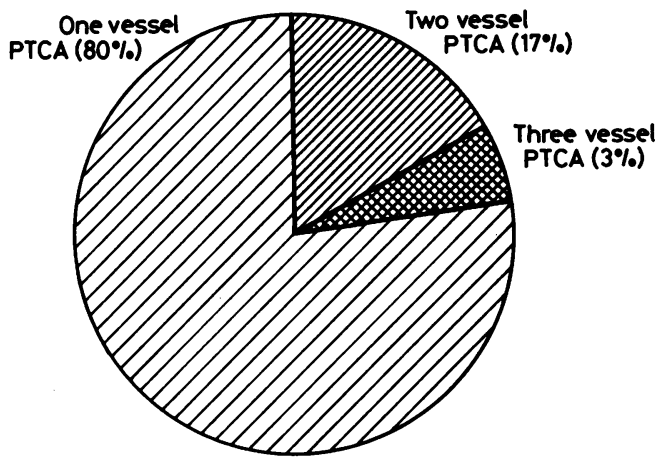

Fig 1 Distribution of single and multivessel coronary angioplasty procedures. PTCA, percutaneous transluminal coronary angioplasty.

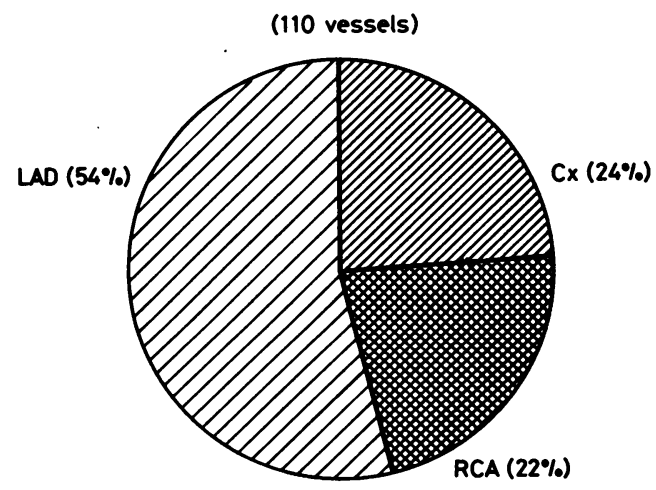

Fig 2 Distribution of vessels attempted. LAD, left anterior descending; $C x$, circumflex; $R C A$, right coronary artery. 
(21 patients)

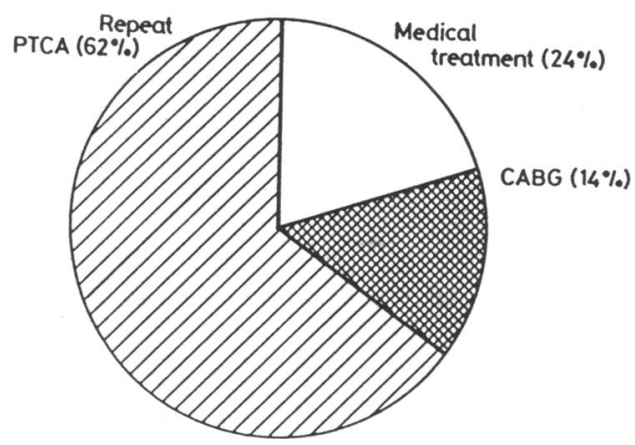

Fig 3 Treatment of restenosis. PTCA, percutaneous transluminal coronary angioplasty; $C A B G$, coronary artery bypass graft.

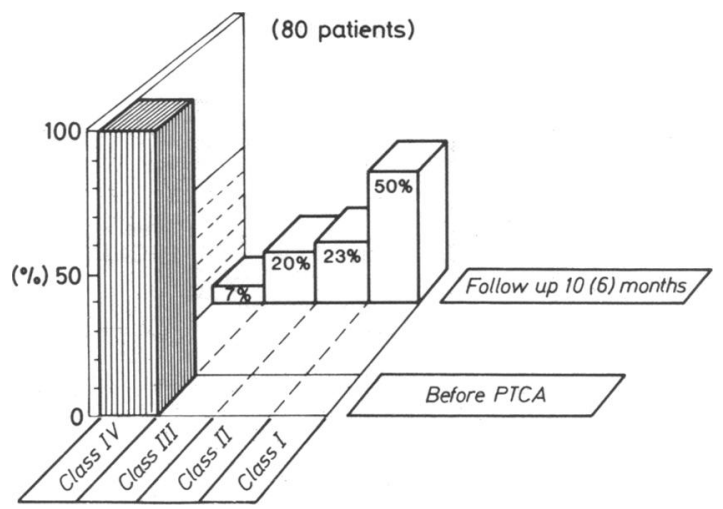

Fig 4 Clinical follow up of patients after the last successful angioplasty procedure. PTCA, percutaneous transluminal coronary angioplasty.

dilated vessels) from $54(15)$ to $14(10) \mathrm{mm} \mathrm{Hg}$. Of 31 patients with multivessel disease, 15 had a successful complete revascularisation and in 13 angioplasty of the ischaemia associated lesions was successful. Acute myocardial infarction was a complication in four patients: two of them had emergency coronary bypass grafting. There were five additional failures caused by our inability to cross the coronary lesion, which was a total chronic occlusion in four patients. All four patients had sustained an infarction with minimal hypokinesis in the region perfused by the occluded vessel and had a severe stenosis on other vessels, with visible collaterals in two patients.

Follow up coronary angiography was performed at a mean (SD) interval of 10 (6) months (range 2-23 months) in $57(71 \%)$ patients: it showed recurrence of stenosis in $21(37 \%)$. Recurrence was recorded in $17(35 \%)$ of 48 patients who had angioplasty of a $c$. single vessel and in $4(44 \%)$ of nine patients who had $\vec{\Rightarrow}$ multivessel angioplasty (NS). Repeat angioplasty (fig 3) was performed in 13 patients and it was suc- 을 cessful in 12; one patient needed emergency coronary surgery because acute coronary occlusion $\frac{0}{\overrightarrow{0}}$ occurred as a complication of the procedure. Three $\mathbb{\Phi}$ patients underwent elective coronary bypass graft- is ing for the treatment of restenosis.

A clinical follow up was available for all patients with initially successful angioplasty at a mean interval of $10(6)$ months after the last successful dilatation procedure. There were no deaths. One patient had sustained an acute myocardial infarction $\mathrm{O}$ unrelated to the dilated vessel. Seventy four $(93 \%)$ ir patients had improved by at least one New York $\vec{\oplus}$ Heart Association class for angina and $41(50 \%)$ were symptom free (fig 4$)$. At follow up $10(80 \%)$ of 13 patients with multivessel disease and successful angioplasty of only the ischaemia related lesions were symptom free or had only mild angina. A stress test was performed in 52 patients as a part of the $ळ$ follow up evaluation at a mean interval of $12(5)$. months (range 4-20 months) from the last coronary angioplasty procedure. Forty patients $(77 \%)$ had neither signs nor symptoms of myocardial ischaemia at a mean workload of 117 (39) W (range 25-200 W) and a mean (SD) double product (blood pressure $\times$ heart rate) of 28000 (6300) $\mathrm{mg} \mathrm{Hg} / \mathrm{min}$. Twelve patients $(23 \%)$ had angina or signs of myocardial $\exists$ ischaemia or both at a mean workload of 104 (35) W (range $50-175 \mathrm{~W}$ ) and a mean double product of 25000 (5500) $\mathrm{mm} \mathrm{Hg} / \mathrm{min}$.

\section{Discussion}

The primary success rate in most reports of coronary angioplasty for unstable angina ranges from $₹$ $61 \%$ in earlier studies ${ }^{8}$ to $93 \%$ in more recent series 응 when steerable systems were used. ${ }^{9}$ Acute complications were reported in seven to $12 \% \cdot .^{9-11}$ Our success rate $(90 \%)$ and complication rate $(5 \%)$ compare favourably with these reports and to some extent 0 may reflect the inclusion in our series of patients $N$ with less severe coronary lesions. Coronary angio- స్ graphy was performed at follow up in $71 \%$ of our $\sigma$ patients after a successful angioplasty. The patients 0 in our series who declined follow up coronary angiography were usually symptom free. In $37 \%$ of our ? patients recurrence of stenosis was seen at angio- $T$ graphy. This rate is higher than in other reports in which restenosis rates for patients with unstable angina ranged from $24 \%{ }^{7}$ to $32 \%$. ${ }^{11}$

All our patients in whom angioplasty was successful had an immediate and considerable improvement 
in anginal symptoms. One patient sustained a myocardial infarction on a non-dilated vessel during the follow up period. Others have reported a similarly low frequency of infarction after a successful angioplasty for unstable angina. ${ }^{911} \mathrm{~A}$ definite symptomatic improvement was apparent $10(6)$ months after the last successful dilatation procedure in about two thirds of our patients, and one half of them were symptom free and with no sign of myocardial ischaemia on a stress test. Long term clinical improvement also persisted in the subset of patients with incomplete myocardial revascularisation- $-80 \%$ of them were either symptom free or had only mild angina. This accords with other reports of incomplete myocardial revascularisation by coronary angioplasty in patients with unstable angina. ${ }^{1012}$ Our data support observations that coronary angioplasty can be performed at an acceptable risk in selected patients with unstable angina. Immediate symptomatic improvement was achieved after a successful angioplasty of the angina related lesions and also in patients in whom myocardial revascularisation was incomplete. Long term improvement of angina was achieved in most patients; in some this required repeated coronary angioplasty.

\section{References}

1 Mulcahy R, Daly L, Graham I, et al. Unstable angina: natural history and determinants of prognosis. $\mathrm{Am} \mathrm{J}$ Cardiol 1981;48:525-31.

2 Unstable angina pectoris: National cooperative study group to compare surgical and medical therapy. II. In-hospital experience and initial follow-up results in patients with one-, two-, and three-vessel disease. Am J Cardiol 1978;42:839-48.

3 Hultgren HN, Shettigar R, Miller DC. Medical versus surgical treatment of unstable angina. Am J Cardiol 1982;50:663-70.

4 Gerstenblith G, Ouyang P, Achuff S, et al. Nifedipine in unstable angina: a double-blind, randomized trial. $N$ Engl J Med 1982;306:885-9.

5 Gottlieb S, Weisfeldt M, Ouyang P, Mellitis D, Gerstenblith G. Silent ischaemia as a marker for early unfavourable outcomes in patients with unstable angina. $N$ Engl J Med 1986;314:1214-9.

6 Williams D, Riley R, Singh A, Gewirtz H, Most A. Evaluation of the role of coronary angioplasty in patients with unstable angina pectoris. Am Heart $J$ 1981;102:1-9.

7 Meyer J, Schmitz HJ, Kiesslich T, et al. Percutaneous transluminal coronary angioplasty in patients with stable and unstable angina pectoris: analysis of early and late results. Am Heart J 1983;106:973-80.

8 Faxon D, Detre K, McCabe C, et al. Role of percutaneous transluminal coronary angioplasty in the treatment of unstable angina. Report from the National Heart, Lung, and Blood Institute Percutaneous Transluminal Coronary Angioplasty and Coronary Artery Surgery Study registries. Am J Cardiol 1983;53:131C-5C.

9 De Feyter P, Serruys P, van den Brand M, et al. Emergency coronary angioplasty in refractory unstable angina. $N$ Engl $J$ Med 1985;313:342-6.

10 De Feyter P, Serruys P, Arnold A, et al. Coronary angioplasty of the unstable angina related vessel in patients with multivessel disease. Eur Heart $J$ 1986;7:460-7.

11 Quigley PJ, Erwin J, Maurer BJ, Walsh MJ, Gearty GF. Percutaneous transluminal coronary angioplasty in unstable angina: comparison with stable angina. Br Heart J 1966;55:227-30.

12 Wohlgelehrnter D, Cleman M, Highman HA, Zaret BL. Percutaneous transluminal coronary angioplasty of the "culprit lesion" for management of unstable angina pectoris in patients with multivessel coronary artery disease. Am J Cardiol 1986;58:460-4.

13 Meier B, Rutishauser W. Transluminal coronary angioplasty-state of the art 1984. Acta Med Scand 1985;70 (suppl):142-6. 